\title{
Menanggulangi Kesalahan Pengobatan Bagi Pasien Peserta BPJS Di Depo Farmasi Rawat Jalan Salah Satu Rumah Sakit Bandung
}

\section{Treatment Medication Errors For BPJS Participants In Depo Pharmacy Out Patient On Of The Hospital Bandung}

\author{
Eva Kusumahati ${ }^{*}$, Ani Anggriani, Choirul Anik \\ Sekolah Tinggi Farmasi Bandung \\ Jl Soekarno Hatta no 754
}

Submitted : 20 -09-2018

Reviewed : 21-09-2018

Accepted : 27 -09-2018

\begin{abstract}
ABSTRAK
Kesalahan pengobatan dapat terjadi pada semua tahap mulai dari peresepan, penyiapan dan penyerahan. Tujuan penelitian ini mengkaji kesalahan pengobatan yang terjadi pada proses pelayanan farmasi dan menganalisis akar masalah penyebab kegagalan untuk tindakan perbaikan dan menanggulangi kejadian kesalahan pengobatan. Metode Penelitian dilakukan secara observasional, pengambilan data secara konkuren terhadap resep rawat jalan pasien BPJS yang dilakukan pada bulan Maret-Mei 2018. Data yang diambil yaitu kelengkapan resep, frekuensi kejadian kesalahan penyiapan dan data kelengkapan pemberian informasi obat. Pada fase peresepan ditemukan tipe kesalahan KPC dan KNC. Pada fase penyiapan ditemukan 95 kejadian kesalahan, tahap penerimaan dan pengkajian resep tidak ditemukan kesalahan, dua temuan pada tahap pengkajian administrasi peraturan $(2,11 \%), 49$ temuan terjadi pada tahap entri data $(51,58 \%), 25$ temuan terjadi pada tahap pengambilan obat $(26,32 \%)$, 4 temuan pada tahap pengisian obat $(4,21 \%)$, dan 15 temuan terjadi pada tahap pemeriksaan akhir $(15,79 \%)$. Berdasarkan tipe kesalahannya, tipe kesalahan KPC 9 temuan (9,5\%), KNC 69 temuan (72,63\%), dan KTC 17 temuan (17,89\%). Pada fase penyerahan obat pemberian informasi cenderung tidak pernah diberikan seperti cara mengatasi terjadi efek samping. Analisis efek dan mode kegagalan dilakukan perhitungan kegawatdaruratan. Tahap yang paling beresiko adalah pengambilan obat (RPN 125) dan entri data (RPN 100) dan akan dianalisis akar masalah. Kesimpulan: Kesalahan yang paling beresiko adalah tahap pengambilan obat dan entri data, Cara menanggulangi kesalahan pengobatan yang terulang menandakan kesalahan system maka perlu monitoring untuk diuji coba didepo famasi rawat jalan terutama untuk pasien BPJS dalam mencegah terjadinya kegagalan di rumah sakit.
\end{abstract}

Kata Kunci : kegagalan pengobatan, mode kegagalan dan analisis efek, analisis akar masalah 
Medication errors can occur at all stages from prescribing, preparing and submitting. to examine medication errors that occur in the pharmaceutical service process and to analyze the root causes of failure for remedial actions and to overcome the occurrence of medication errors. Methods: The study was conducted observationally, concurrent data retrieval of prescription outpatient BPJS patients carried out in March-May 2018. Completeness of prescription, frequency of occurrence of errors and preparation of complete drug information. Results: In the prescribing phase found the KPC and KNC error types. In the preparation phase found 95 occurrences of errors, the stage of receiving and reviewing prescriptions not found errors, two findings at the administrative administration review stage (2.11\%), 49 findings occurred at the data entry stage (51.58\%), 25 findings occurred at the stage taking drugs (26.32\%), 4 findings at the stage of drug filling (4.21\%), and 15 findings occurred at the final examination stage (15.79\%). Based on the type of error, 9 types of KPC errors were found (9.5\%), KNC 69 findings (72.63\%), and KTC 17 findings (17.89\%). During the delivery phase, information giving drugs tend to never be given such as how to overcome side effects. Effect analysis and failure mode are carried out by calculating emergency. The most risky stage is taking the drug (RPN 125) and data entry (RPN 100) and will analyze the root of the problem., the way to cope with repeated medication errors, it is necessary to re-design the system, monitoring treatment, especially for BPJS patients in preventing hospital failure.

Keywords: treatment failure, failure mode and effect analysis, root cause analysis

\section{Penulis korespondensi:}

Eva Kusumahati

Sekolah Tinggi Farmasi Bandung

Jl. Soekarno Hatta No.754 Bandung

Email: eva.kusumahati@stfb.ac.id

\section{PENDAHULUAN}

Kesalahan pengobatan (medication error) adalah kejadian yang merugikan pasien, akibat pemakaian obat selama dalam penenganan tenaga kesehatan, yang sebetulnya dapat dicegah (Depkes RI, 2008). Kesalahan pengobatan dapat terjadi pada masing-masing proses dari peresepan, mulai dari penulisan resep, pembacaan resep oleh apoteker, penyerahan obat sampai penggunaan obat oleh pasien. Sebuah studi yang dilakukan oleh Anny Victor Purba, dkk di Yogyakarta terhadap sebuah rumah sakit swasta menunjukkan bahwa dari 229 resep, ditemukan 226 resep medication error. Dari 226 medication errors, 99.12\% merupakan kesalahan peresepan, 3.02\% merupakan kesalahan farmasetik dan 3.66\% merupakan kesalahan penyerahan. 58\% Kesalahan pengobatan tertinggi terjadi di depo farmasi rawat jalan (Purba, 2007).

Monitoring keamanan dan efikasi obat secara adekuat dapat mencegah terjadinya efek samping. Di Rumah Sakit, pemberian informasi dan kontrol administrasi obat merupakan tantangan yang berat. Selain itu, khusus pada pasien peserta BPJS yang berobat rawat jalan, saat ini kontrol penggunaan obat dan keparahan efek samping juga belum dimonitor dengan baik. Sesuai dengan undang-undang nomor 24 tahun 2011, BPJS (Badan Penyelenggara Jaminan Sosial) kesehatan merupakan lembaga penyelenggara program jaminan social bagi seluruh warga Indonesia yang salah satu tugasnya adalah untuk membantu memastikan bahwa pasien mendapatkan penggunaan obat yang terbaik dan rasional.

Beberapa upaya untuk meningkatkan kualitas pelayanan BPJS seperti kelayakan mitra fasilitas kesehatan, pembuatan formularium nasional, aplikasi INACbg dan sebagainya, hal-hal tersebut dilakukan agar dampak negatif dari medication error seperti pemborosan dari segi ekonomi dan menurunnya mutu pelayanan pengobatan (meningkatnya 
efek samping dan kegagalan pengobatan) dapat diminimalkan. Namun hasilnya belum efektif, biaya obat rawat jalan yang harus dikeluarkan BPJS semakin meningkat dan menurut hasil wawancara dengan verifikator BPJS, masih banyak fasilitas kesehatan yang melakukan kesalahan pengobatan secara administratif, hal ini berpotensi terhadap kesalahan pengobatan pada saat dilakukannya pelayanan didepo farmasi rumah sakit, sehingga perlu dilakukan penelitian untuk mengkaji kesalahan pengobatan yang terjadi pada proses pelayanan farmasi dan menganalisis akar masalah penyebab kegagalan sehingga diperoleh cara menanggulangi kesalahan pengobatan.

Penelitian ini bertujuan untuk mengkaji kesalahan pengobatan yang terjadi pada proses pelayanan farmasi dan menganalisa akar masalah penyebab kegagalan untuk tindakan perbaikan serta diharapkan dapat menekan angka kejadian kesalahan pengobatan.

\section{METODE PENELITIAN}

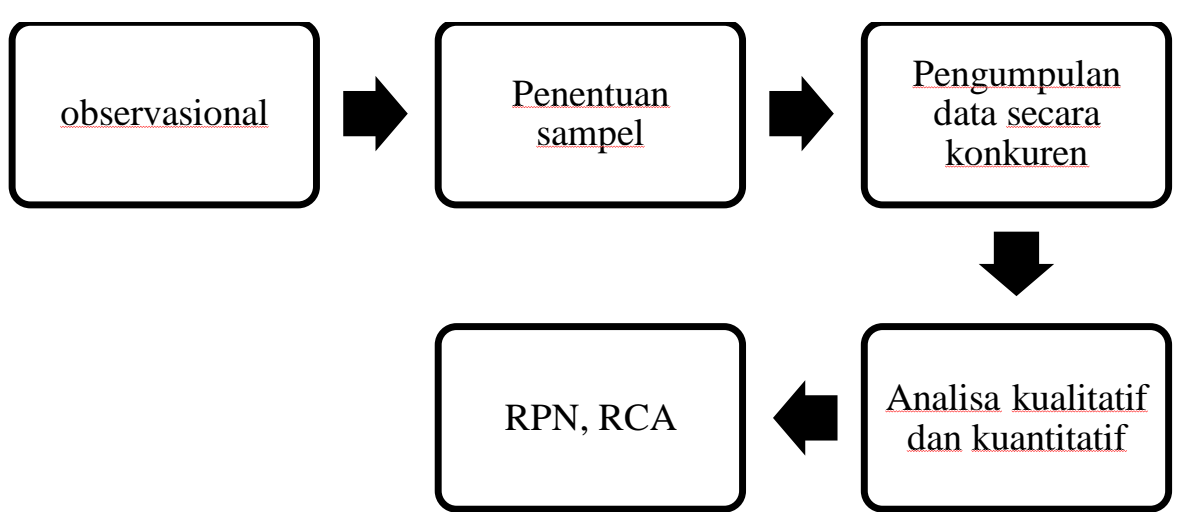

\section{Desain Penelitian}

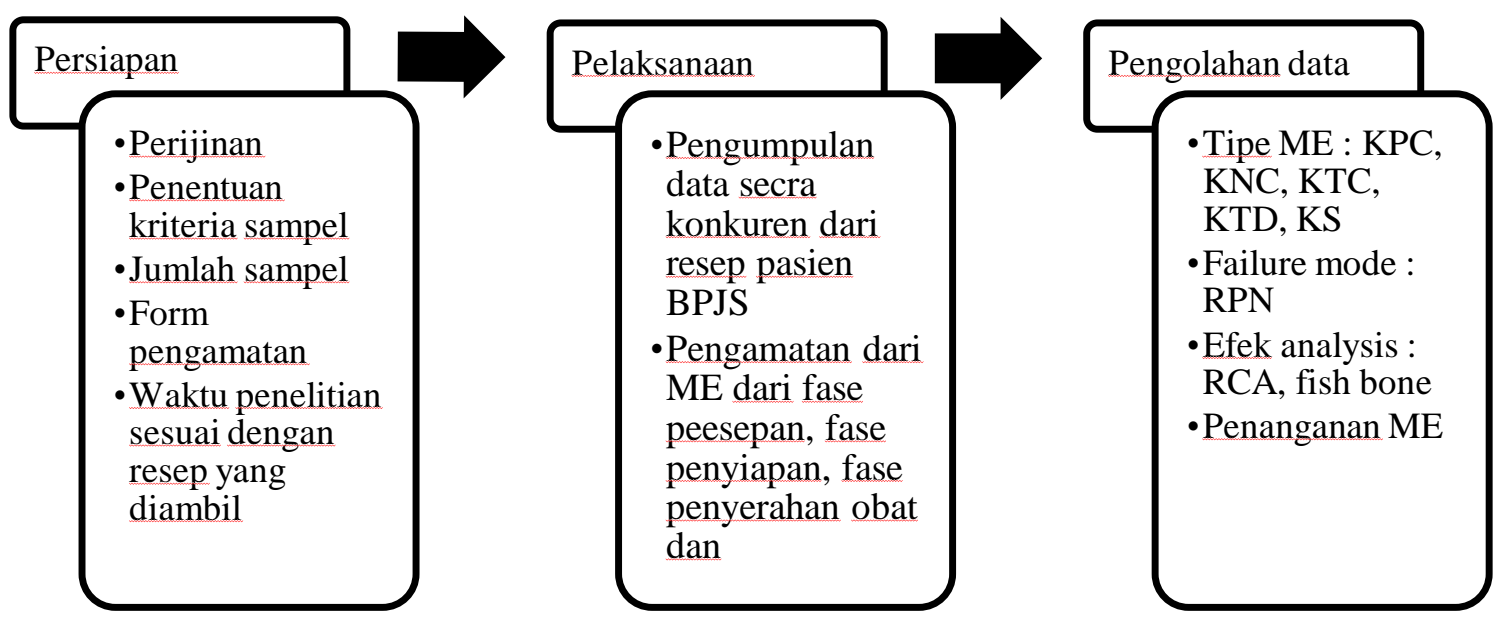

\section{HASIL DAN PEMBAHASAN}

Penelitian yang telah dilakukan pada resep di depo farmasi rawat jalan pada bulan MaretMei 2018 secara konkuren pada pukul 08.00-16.00 WIB. Berdasarkan data resep sebelumnya, depo melayani 800 pasien per hari, dalam sebulan sekitar 24.000 resep. Maka didapatkan jumlah sampel 400 lembar perbulan, atau 10lembar resep per hari, yang 
dilakukan selama 2 bulan, resep diamati selama 40 hari kerja. Penentuan kelengkapan resep mengacu Peraturan Menteri kesehatan RI no 72 tahun 2016 tentang Standar Pelayanan Kefarmasian di Rumah Sakit, bab III Pelayanan Farmasi Klinik, subbab Pengkajian dan Pelayanan Resep dan dinilai apakah terjadi kesalahan baik dari peresepan, penyiapan dan penyerahan obat.

1. Fase Peresepan

Tabel III. Frekuensi Kejadian Kesalahan Peresepan

\begin{tabular}{lllll}
\hline Aspek & Deskripsi & $\begin{array}{l}\text { Tipe } \\
\text { kesalahan }\end{array}$ & jumlah & $\%$ \\
\hline Usia pasien & Tidak tertulis & KPC & 50 & 12,5 \\
$\begin{array}{l}\text { Bobot badan } \\
\text { Tinggi badan }\end{array}$ & Tidak tertulis & KPC & 361 & 90,25 \\
$\begin{array}{l}\text { Bentuk sediaan } \\
\text { obat }\end{array}$ & Tidak tertulis & KPC & 400 & 100 \\
$\begin{array}{l}\text { Kekuatan } \\
\text { sediaan }\end{array}$ & Tidak tertulis & KPC & 312 & 21,68 \\
$\begin{array}{l}\text { Aturan/cara } \\
\text { penggunaan }\end{array}$ & Tidak tertulis & KPC & 28 & 193 \\
$\begin{array}{l}\text { Dosis } \\
\text { Duplikasi }\end{array}$ & $\begin{array}{l}\text { kosis } \\
\text { Terang/lebih } \\
\text { duplikasi }\end{array}$ & KNC & 2 & 0,13 \\
Interaksi Obat & $\begin{array}{l}\text { Ada interaksi } \\
\text { obat KPC } \\
\text { mungkin terjadi }\end{array}$ & & 14 & 0,88 \\
& & & 155 & 9,78 \\
\hline
\end{tabular}

2. Fase Penyiapan

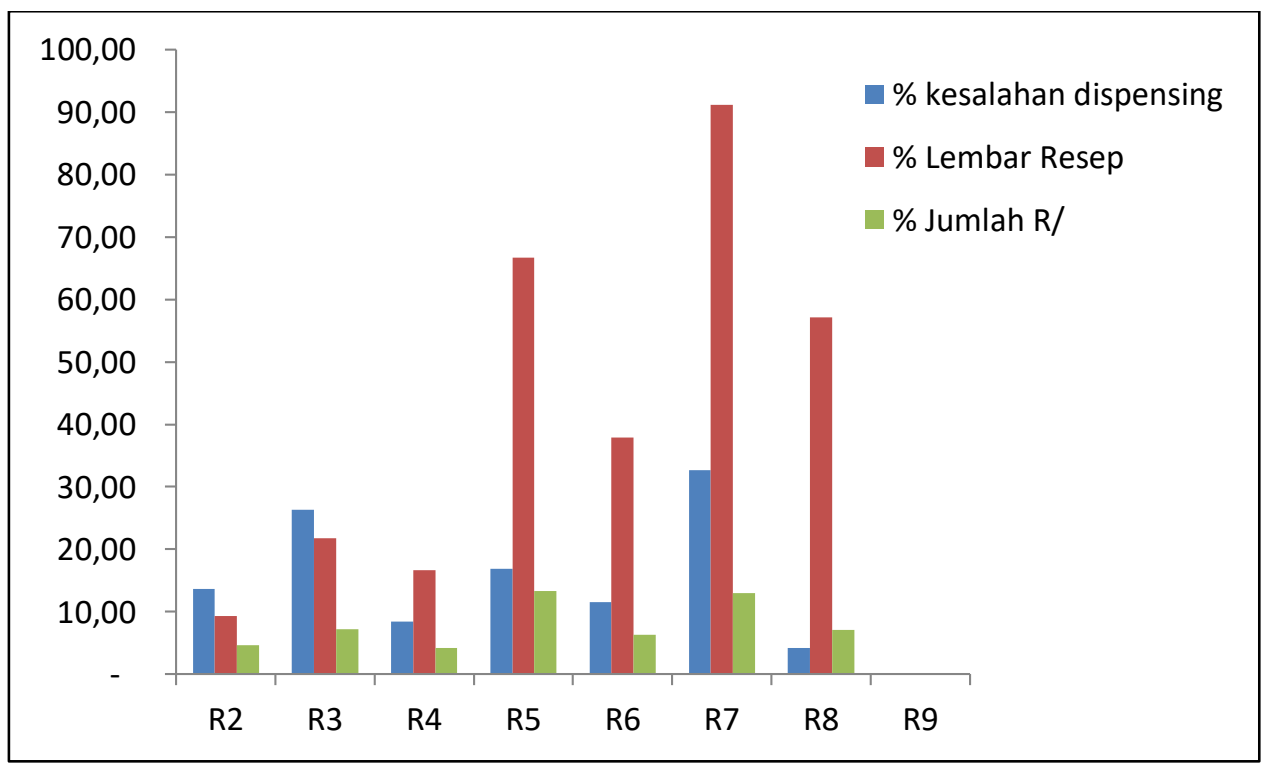

Gambar 1. Grafik Frekuensi Kesalahan Dispensing Berdasarkan Jumlah Resep 


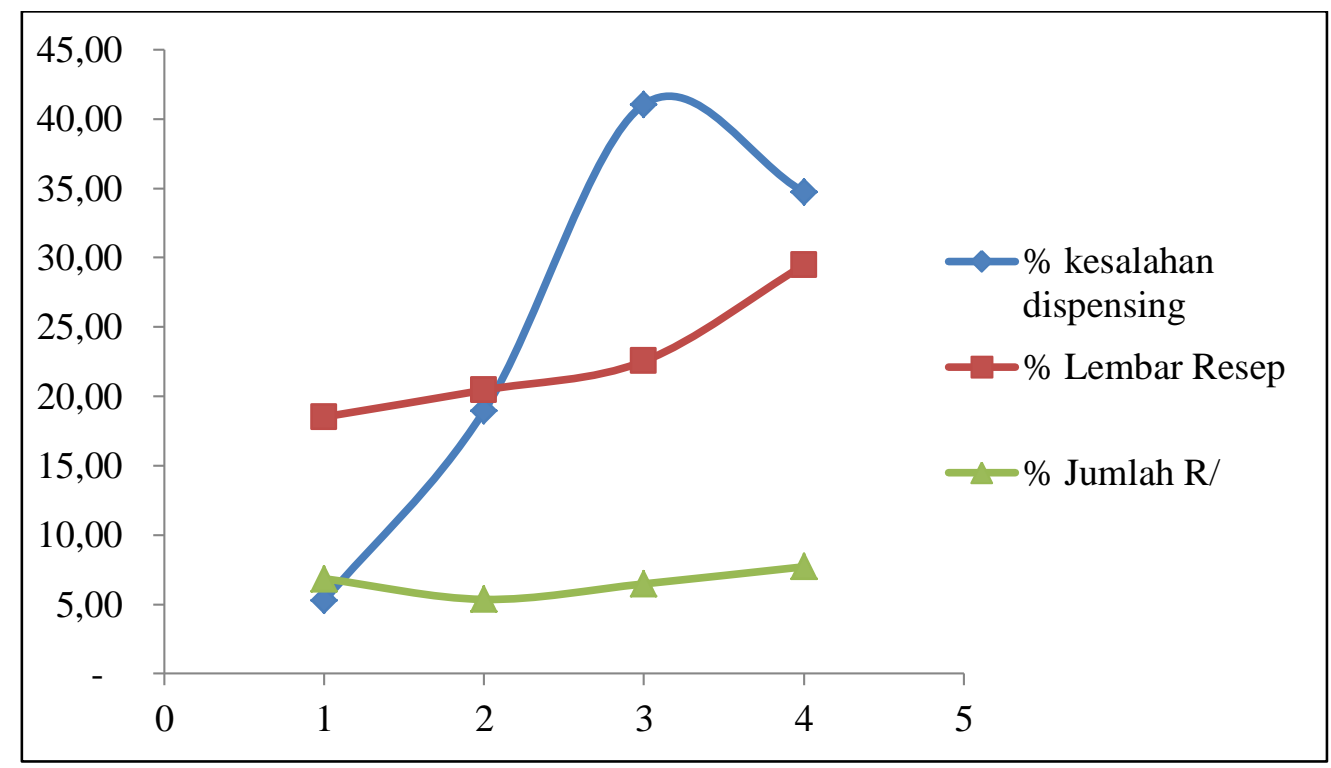

Ket $: \operatorname{angka} 1=$ jam 8 , angka $2=$ jam 9 , angka $3=$ jam 10 , angka $4=$ jam 11 , angka $5=$ jam 12

\section{Gambar 2. Grafik frekuensi kesalahan dispensing bedasarkan waktu}

Tabel II. Frekuensi Kejadian Kesalahan Semua Tahap Dispensing

\begin{tabular}{lcc}
\hline \multicolumn{1}{c}{ Dispensing (D) } & Jumlah & \% \\
\hline D1 Penerimaan resep & 0 & 0 \\
D2 Pengkajian resep & 0 & 0 \\
D3 Pengkajian administrasi peraturan & 2 & 2,11 \\
D4 Entri data & 49 & 51,58 \\
D5 Pengambilan obat & 25 & 26,32 \\
D6 Pengisian obat & 4 & 4,21 \\
D7 Pemeriksaan akhir & 15 & 15,79 \\
Total & 95 & 100 \\
\hline
\end{tabular}

Tabel III. Frekuensi Kejadian Kesalahan Dispensing Berdasarkan Tipe Kesalahan

\begin{tabular}{lccccc}
\hline \multirow{2}{*}{$\begin{array}{c}\text { Dispensing } \\
\text { (D) }\end{array}$} & \multicolumn{5}{c}{ Tipe kesalahan } \\
\cline { 2 - 6 } & KPC & KNC & KTC & KTD & KS \\
\hline D1 & $\mathbf{0}$ & 0 & 0 & 0 & 0 \\
D2 & $\mathbf{0}$ & 0 & 0 & 0 & 0 \\
D3 & 2 & 0 & 0 & 0 & 0 \\
D4 & 5 & 44 & 0 & 0 & 0 \\
D5 & 0 & 25 & 0 & 0 & 0 \\
D6 & 2 & 0 & 2 & 0 & 0 \\
D7 & 0 & 0 & 15 & 0 & 0 \\
\hline Jumlah & 9 & 69 & 17 & 0 & 0 \\
\hline \% & 9,5 & 72,63 & 17,89 & 0 & 0 \\
\hline
\end{tabular}


3. Tahap penyerahan obat dan pemberian informasi

Tahap penyerahan obat dan pemberian informasi diamati kelengkapan informasi obat yang diberikan oleh petugas farmasi kepada pasien.

\section{Tabel IV. Kelengkapan Pemberian Informasi Obat Tahap Penyerahan Obat}

\begin{tabular}{lcc}
\hline Informasi & Jumlah & \% \\
\hline Menanyakan nomor resep/antrian & 400 & 100 \\
Menanyakan nama pasien & 400 & 100 \\
Menanyakan usia/tgl lahir & 5 & 1,25 \\
Menanyakan alamat pasien & 16 & 4 \\
Menanyakan nomor telepon & 400 & 100 \\
Nama obat & 400 & 100 \\
Indikasi obat & 400 & 100 \\
Dosis & 25 & 6,25 \\
Aturan pakai & 312 & 78 \\
Bentuk sediaan obat & 4 & 1 \\
Waktu penggunaan & 200 & 50 \\
Jumlah obat & 2 & 0,5 \\
Teknik penggunaan obat khusus & 0 & 0 \\
Cara penyimpanan obat & 0 & 0 \\
Jadwal pengambilan obat berikutnya & 8 & 2 \\
Apa yang dilakukan jika lupa minum obat & 0 & 0 \\
efek samping dan mengatasinya & 0 & 0 \\
\hline
\end{tabular}

\section{Failure Mode and effect Analysis}

Bedasarkan perhitungan RPN diatas, mode kegagalan tetinggi adalah kegagalan dalam mengambil obat (RPN 125) dan kegagalan dalam entri obat (RPN 100). Kemudian skor tertinggi ini akan dilakukan anaisis akar penyebab masalah terjadi kesalahan dilihat dari factor manuasi, material, metode, sarana/prasaana dan lingkungan yang dapat terlihat pada Tabel V. 
Tabel V. Akar Masalah Kegagalan Mengambil Obat dan Kegagalan Entri Data

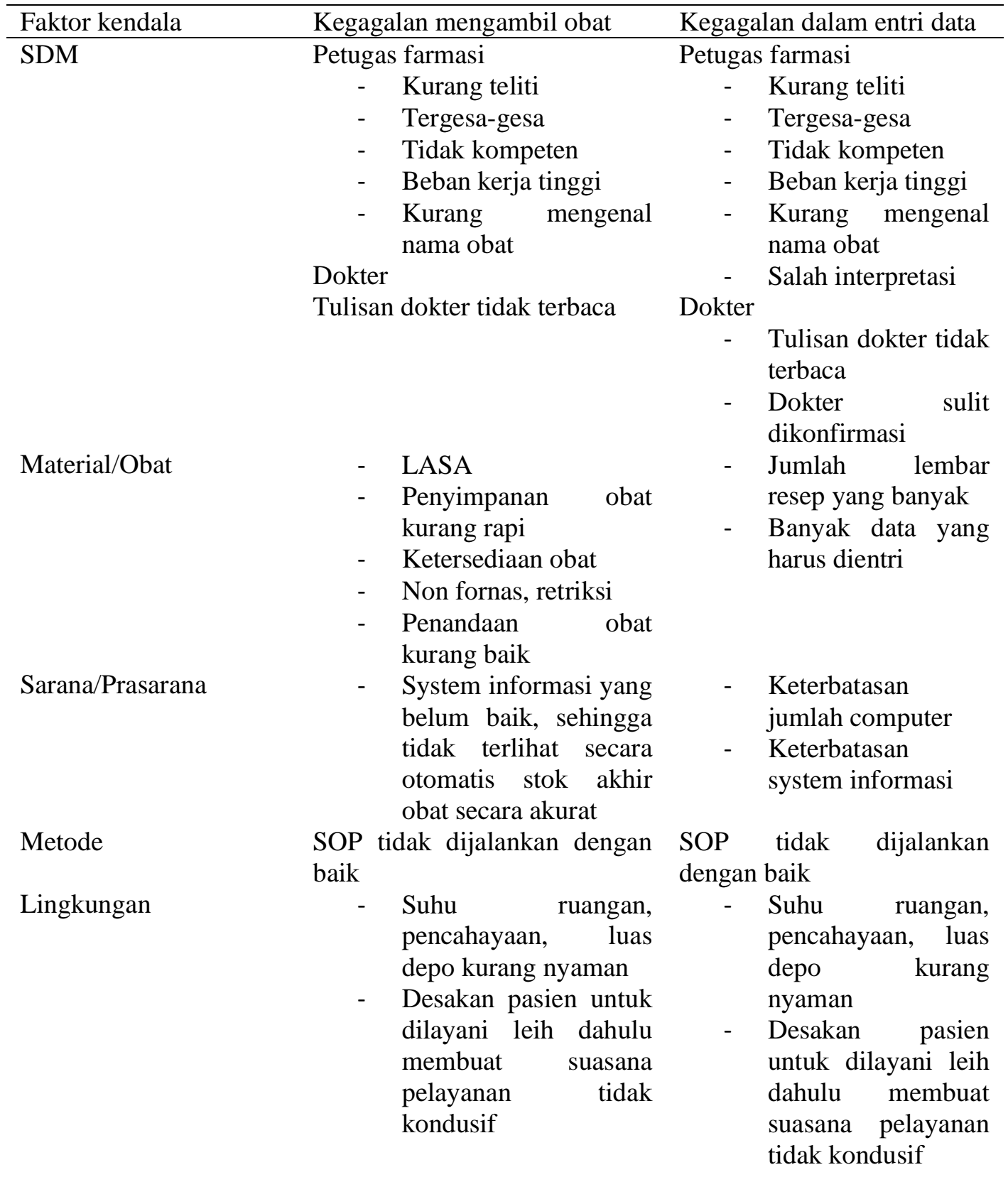

\section{KESIMPULAN}

Analisis efek dan mode kegagalan (FMEA/failure mode and effect analysis), tahap yang paling beresiko adalah pengambilan obat (RPN 125) dan entri data (RPN 100). Cara menanggulangi kesalahan pengobatan yang terulang maka perlu dibuat rancangan ulang sistem. 



\section{DAFTAR PUSTAKA}

Apriani, K. 2016. Gambaran Kejadian Nyaris Cedera (KNC) pada pelayanan kefarmasian diapotek rawat inap RS Dr. mintohardjo. Skripsi, Fakultas kedokteran dan ilmu kesehatan : UIN syarif Hidayatullah. Jakarta.

Ballard, K.A. 2003. Patient Safety. A shared responsibility. Online Journal of Issue in Nursing. Volume 8 no 3

Cindersuci, R. 2012. Perbaikan Angka Kejadian Tidak Diharapkan Dengan Metode Six Sigma di Instalasi Rawat Inap RS Anna Medika Bekasi Tahun 2011. Tesis Fakultas MIPA : Universitas Indonesia

Departemen Kesehatan Republik Indonesia. 2008. Tanggung Jawab Apoteker Terhadap Keselamatan Pasien (Pasien Safety), Jakarta.

Greenall, J., Walsh, D. dan Wichman, K. 2007. Failure Mode and effect analysis: A tool for identifiying risk in community pharmacies, ISMP Canada

Purba, A.V., Soleha, M dan Sari, I.D. 2007. Kesalahan dalam Pelayanan Obat (medication error) dan Usaha Penceghannya, Buletin Penelitian Sistem Kesehatan, Volume 10, Januari 2007

RSUD Al Ikhsan. 2016. Pedoman Penulisan Resep dan Kartu Obat Pasien di RSUD Al Ikhsan Bandung, Bandung

Tatro, D.S. 2008. Drug Interaction Facts. St. Louis, Missouri, Wolters Klower Health 